\title{
The Study of China's Water Resources Governance Emphasis and Model Innovation During the Thirteenth Five-Year Plan Period
}

\author{
Limin Dong ${ }^{1, a}$, Guojun $\mathrm{Li}^{2, \mathrm{~b}}$, Xu Chen ${ }^{3, \mathrm{c}}$ and Ping Dong ${ }^{4, \mathrm{~d}^{*}}$
}

${ }^{1}$ Instituteof Economics and business administration, Central China Normal University,Wuhan, Hubei, China

${ }^{2}$ Instituteof Economics and business administration, Central China Normal University,Wuhan, Hubei, China

${ }^{3}$ Instituteof Economics and business administration, Central China Normal University,Wuhan, Hubei, China

\author{
${ }^{4}$ Instituteof Geography and oceanography, Nanjing University,Nanjing, Jiangsu, China \\ adlm6805@126.com, b215963685@qq.com, ckellychanmax@gmail.com, d2246453962@qq.com
}

Keywords: The 13th Five-Year Plan Period; Water resources governance; People's livelihoods; Model innovation; Water ecological environment

Abstract. Currently China's water resources have met many problems, such as water resources shortage, water pollution phenomenon, flood and drought coexistence, water ecological environment deterioration and so on. Based on the series of objective facts, this paper from international and domestic visuals analyses what challenges and opportunities water resources will encounter with in the new environment. Then it illustrates the unsolved problems of water resources from perspectives of system, market, technology and policy. At last, according to the status and features of water resources governance in our country, creative and constructive coping strategies have been put forward as a reference.

\section{Introduction}

Water as a natural resource and an important strategic resource is significant to support the social and economic development. In recent years, accompanied by events such as droughts, floods, water pollution and water crisis which occurred frequently, water shortage in some extent restricted the economic development in some areas, affecting people's normal living standards and health benefits. The seriousness and urgency of the problems of water resources has attracted much attention from scholars and government officials.

The 13th Five Year Plan Period is a crucial stage of the completion of a comprehensive well-off society in China as well as the deepening of reform in key areas for achieving decisive outcomes[1]. In this stage, changes will be made over the economic structure and the development pattern, new policies will gradually be introduced and the reform will be increasingly deepened. Environmental protection therefore will encounter with challenges and opportunities in transition. When it comes to environmental protection, Xi Jinping pointed out that to build a good ecological environment is the growth point of improving people's quality of life as well as a start point to show the good image of our country[2]. Laying equal stress on ecological environment and economic growth and vigorously developing green economy and circular economy will be put great emphasis on in the environmental aspect of the 13th Five-Year Plan.

Since great opportunities and serious challenges coexist in the governance of water resources, the government need to seize the opportunity and do the overall planning work, seek advantages while avoid disadvantages and commit to building an integrated and comprehensive management system of water resources which may greatly alleviate the water shortage situation, promoting sustainable development of water resources and eventually achieving the harmony between human and natural resources.

\section{Current Problems of Water Resources Governance.}

As one of the controlling factors of the ecological environment, water resources are closely related to our standard of living, economic development, ecological construction etc. Taking a panoramic view 
of the current situation of water resources in our country, we are mainly facing problems as following aspects:

From the perspective of institutional system, compared with the institutional mechanisms and the organizational structures of water resources in foreign countries, China exists issues of fairness and efficiency, for example, the unknown subject of the watershed management and the unfair division of the organic whole of the water resources. In addition, national laws and regulations concerning water management system are still not sound. Problems such as the lack of management planning and rigid system of the environmental management remain to be resolved.

In regard to the market system, for a long time, China's water resources system has many loopholes and defects, for example, the ownership is not clear, the price mechanism is not sound, the water pricing is unreasonably imposed, water resources fund is in shortage, the government is overburdened and so on[3]. It is precisely the existence of these problems that led to the deterioration of the ecological environment of water and the water crisis which has become more and more prominent.

Despite a large number of theoretical and practical research on water governance policy have been carried out in China, the unified and rational policy system has not yet been formed due to the mismanagement and the unsound market of water management.

Technically, compared to other western countries, the research and development on environmental technology in China is quite limited; the time and funds invested in integration and application is far from sufficient as well. In addition, Water remediation technology of ecological carrying capacity, ecological environment improvement, network construction of water monitoring and waste water reprocessing have not been demonstrated on a comprehensively wide scale.

\section{Strategic Opportunities for Water Resources in the 13th Five Year Plan Period.}

The problem of Water resources is not only a tough problem in China, but also a focus of other countries in the world. Resolving the environmental problems will meet unprecedented great opportunities in the 13th Five Year Plan Period.

For one thing, even though the practice of water resources management in different countries is not the same, some experience and lessons are worth being regarded as our reference. For example, Britain and France is based on watershed management system while Holland applies a coordinated model, balancing the interests of the administrative areas and the river basin. And some countries take the administrative boundaries as the basis of the management system[4]. For another, with the further development of economic globalization, the whole world continue to strengthen technological exchanges and economic cooperation, which also provides a strong support for China's water resources governance. Since twenty-first century, the majority of experts and scholars recognize that, whether developing or developed countries, are more or less faced with different water issues. Strengthening cooperation and exchanges with other countries combined with domestic status could save plenty of time and effort as well as improve the efficiency and effectiveness of water resources management.

Domestically, a wide range of space for the development of water resources governance could be provided during the critical 13th Five Year Plan Period. In this stage, GDP grows in medium-high speed, the tertiary industry has become the main force driving economic growth, the investment of resources and environment declines and the energy structure is optimized, all of which on the whole are in favor of environmental protection direction.

Next, the strategic position of the ecological environment construction is further rising. From the national leadership and government officials down to the masses, people are extremely concerned about the environmental governance, which provides a policy support and mass foundation for the management of water resources. Besides, the policies, laws and regulations on environmental management and protection will be introduced in succession during this period, which will become the "effective barrier" of the construction of water governance.

In addition, 13th Five Year Plan lays emphasis on people's livelihood, innovation-driven, optimization and upgrading of industrial structure and promotion in new urbanization, strengthen the food security and protection of water resources[5], which will give technical support for the water 
management. On the one hand, the emission intensity will be lowered based on the optimization of the industrial structure and the growing clean energy; on the other hand, water circulation can be better and efficiently used along with the development of water-saving technologies.

Moreover, the rapid development of economy in the 13th Five Year Plan Period will pave the way for water resources management. During this period, all aspects of the construction not only play a significant role in building a well-off society, achieving the strategic goal of deepening reform, and producing a new economic growth point in the continuous reform of industrialization, but also lay a solid foundation for the improvement of national governance capacity.

\section{The Focus and Model Innovation of Water Resources Governance.}

We should have a clear understanding of the water problems and grasp the trend of domestic and international development standing from the present and look forward to the future. Meanwhile, we need to make an objective analysis of challenges and problems in the process of water governance and identify the direction and focus to build a water management system of completion, comprehensiveness and feasibility.

Practice and exploration of water management should be carried out with focuses and based on the present situation and characteristics of water resources governance. Since water management is an extremely complex item, key watersheds and industries should be given priority as pilot projects. The relevant experts and scholars should hold a timely discussion and break the challenges one by one. Finally, the successful experience of the pilot projects could be gradually extended to establish a complete set of comprehensive, practical water management program.

The water governance model should be transferred from the traditional model to an integrated one[6]. The traditional and rigid water governance is a major impediment to achieving effective governance of water resources. Under the policy of the innovation-driven model in 13th Five Year Plan Period, water governance should be integrated, unified, scientific and innovative-oriented to achieve diversification of water resources governance.

We need to learn advanced technology and successful experience from abroad and home, trying to explore and develop the third-party governance[7], which, according to the Third Plenary Session of the Eighteenth, is a typical practice to assist the pollution governance combined with market mechanisms. A new mode of third-party governance can be cultivated through water pollution---one of the most serious environmental pollution in our country.

Based on the existing disadvantages of water resources management system, it is necessary to increase investment on water resources management and actively carry out multi-field, multi-level and multi-disciplinary research to gradually establish a sound, comprehensive, scientific and feasible water resources management system.

\section{Acknowledgements}

Corresponding author: Ping Dong(2246453962@qq.com)

\section{References}

[1] Angang Hu, Yilong Yan, Jiaying Jiang: submitted to Journal of The Reform of the Administrative Management,02(2015). (in Chinese)

[2] Information on http://politics.people.com.cn/n/2015/0529/c99014-27078010.html

[3] Yahua Wang, Angang Hu: submitted to Journal of China Population, Resources and Environment, 05 (2007). (in Chinese)

[4] Jian Xie, Andres Liebenthal, Jeremy Warford. Tackling Water Crisis: How to Solve the Problem of Water Shortage, China CITIC Press, Beijing, 2009, pp.77-78. (in Chinese)

[5] Information on http://business.sohu.com/20141205/n406696811.shtml 
[6] Wensheng Yuan, Junying Yuan, Guoyuan Zhang: submitted to Journal of Science and Technology and Economy of Water Conservancy, 12 (2008). (in Chinese)

[7] Chongmi Gao: submitted to Journal of China Petroleum and Chemical Industry, 01 (2014). (in Chinese)

[8] Jinnan Wang, Shoumin Zhou, Rensheng Tian, Huiyuan Zhang. Environmental Policy Research Series, China Environmental Science Press, Beijing, 2009, pp.418-435. (in Chinese) 